\title{
Pharmacotherapy Regimens
}

National Cancer Institute

\section{Source}

National Cancer Institute. Pharmacotherapy Regimens. NCI Thesaurus. Code C160950.

A set of concepts that are used as regimens to treat a disease. 